\title{
Three Principles of Rationalism
}

\author{
Christopher Peacocke
}

It is just over fifty years since the publication of Quine's 'Two Dogmas of Empiricism' (1951). That paper expresses a broad vision of the system of relations between meaning, experience, and the rational formation of belief. The deepest challenges the paper poses come not from the detailed argument of its first four sections - formidable though that is - but from the visionary material in its last two sections. ${ }^{1}$ It is this visionary material that is likely to force the reader to revise, to deepen, or to rethink her position on fundamental issues about the relations between meaning, experience, rationality, and, above all, the a priori. Does what is right in Quine's argument exclude any rationalist view of these relations? How should a rationalist view be formulated? Those are the questions I will be addressing. I start with the critical part of this task, a consideration of the strengths and weaknesses of Quine's vision. Drawing on the constraints emerging from that critical discussion, I will then turn to the positive task of articulating and defending a rival conception. The rival conception can be described as a Generalized Rationalism.

\section{The Character of the Quinean Challenge}

Quine argued as follows.

(a) Whatever meaning is, and whatever it is that has meaning - whether an individual sentences, group of sentences, or whole theory - meaning must be characterized in terms of the experiences or evidence that would support what it is that has meaning.

(b) For a vast range of individual sentences, experiences or evidential conditions cannot be associated with those sentences one-by-one if the association is meant to capture the meaning of those individual sentences. What experiences one would expect to occur, and what evidence one would expect to exist, given that a particular sentence is true, is frequently heavily dependent upon which other auxiliary sentences are also true.

(c) In the general case, then, experiences or evidence can be associated only with a class of sentences, where the class contains the many auxiliary hypotheses upon which the experiential or evidential consequences of any given sentence also depend. 
(d) Given the truth of (a)-(c), the whole idea of the meaning of an individual sentence being given by a range of supporting experiences or evidence is an illusion. A fortiori, the whole idea of the existence of sentences whose meaning-individuating associated experiential or evidential conditions are always confirmed by the evidence is equally illusory. There are no such meaning-individuating experiential or evidential conditions.

Quine's later writings acknowledge a limited class of sentences that are always confirmed, but this class is far narrower than any traditional conception of the a priori would allow. His own positive view was that rationality in belief-formation is not something constrained by the meaning of the individual sentences whose acceptance is in question. Rationality is rather a pragmatic matter of shaping what one accepts to fit experience or the evidence.

For anyone with even the faintest rationalist sympathies, there is a pressing need to consider Quine's argument. It is extremely plausible that many sentences do indeed not have confirmation conditions considered one-by-one. If there really is a sound argument from this point about confirmation to a rejection of any interesting application for the a priori, any form of rationalism is a nonstarter. Quine seems to have a wholly general argument against the possibility of theoretically significant a priori truth, an argument that applies whatever notion of evidence is used in the explication of meaning. The argument would reach far beyond the reductionist empiricism which forms the content of the second of the two dogmas Quine targets. If sound, his argument against a theoretically interesting notion of the a priori will get a grip in the context of every evidential theory of meaning.

For the purpose of discussing the present issues, an umbrella characterization of the a priori will suffice. A content is a priori if a thinker can be entitled to accept it without that entitlement being constitutively dependent upon the content or kind of her perceptual experiences or other conscious states. The species of dependence in question here is normative, not causal: it is a question of what, constitutively, provides the entitlement, and not merely of what facilitates it. (This is a distinction that has long been drawn by rationalists.) The entitlement may, but need not, be conclusive. A thinker may also be mistaken about whether her entitlement is conclusive. There are many parameters in this characterization that could be set differently. For some purposes it is important to consider different settings, for instance to consider more restrictive characterizations than conscious states in general. But a generalized rationalism will be concerned in the first instance with the possibility of a rationalism that employs the most general settings used here. ${ }^{2}$

In addition to this outright, non-relative characterization of the a priori, there is also a corresponding relativized notion. We can say that a transition from one of the thinker's conscious states to a judged content is an a priori transition if the thinker is entitled to accept that content given that she is in that conscious state, without this relative entitlement being dependent upon the content or kind of any

(c) Blackwell Publishers Ltd. 2002 
of her other perceptual experiences or other conscious states. Consider the demonstrative content 'That rod is curved', where the perceptual-demonstrative component that rod is made available to the thinker by her perception of the rod which she experiences as curved. This content is certainly not outright a priori. Nevertheless, given the occurrence of such an experience, taken at face value, the thinker does not need to rely upon the content or kind of any further experience in coming to make the judgement 'That rod is curved'. As we might equivalently say, the content is relatively a priori, is a priori relative to this perceptual state. The case contrasts with the content 'That rod is bending from differential expansion in the heat'. This content is not even relatively a priori in relation to an experience, taken at face value, of the rod as curved. Any transition from such an experience, taken at face value, to the conclusion that the rod is bending from differential expansion in the heat, is not a priori. Additional information, and/or experiences in addition to the perception of the rod as curved, are required before our thinker is entitled to accept the content that the rod is bending from differential expansion in the heat. Like the outright a priori, the relative a priori need not involve, and will not in general involve, conclusive entitlement.

Neither the outright nor the relative a priori need involve the idea of truth purely in virtue of meaning. Fourteen years before 'Two Dogmas', Quine had already in 'Truth by Convention' argued against the idea that any sentence could be true by convention, or indeed true purely in virtue of meaning alone. In my judgement, the arguments Quine gave there, and especially those given later in 'Carnap and Logical Truth', constitute one of his most enduring contributions to philosophy. ${ }^{3}$ To make clear what it is that I will be opposing to Quine's vision, I should say that my own view, like that of several other current defenders of the a priori, is that Quine's arguments in 'Truth by Convention' and 'Carnap and Logical Truth' are decisive. ${ }^{4}$ The strongest of those arguments are completely free of any commitment to behaviourism or to evidential theories of meaning. Contemporary theorists of the a priori should not be involved with the uninstantiated and uninstantiable notion of 'true purely in virtue of meaning'. ${ }^{5}$

On the limited and specific issue of whether there a priori contents and a priori transitions, Quine's argument has a clear lacuna. Many of those who argue in favour of theoretically interesting forms of the a priori do not accept purely evidential theories of meaning. They will therefore not accept that an a priori content is one whose meaning-constituting evidential conditions are always confirmed by the evidence. Such a theorist may rather hold, for instance, that an outright a priori method of coming to accept a given content $p$ is one with the following distinctive property. It is entailed by the possession conditions for the concepts composing $p$, together with the way their semantic values are determined, and their mode of combination in the content $p$, that use of the 'given method guarantees that $p$ will be true in any world in which the method is applied (see for instance Peacocke 1993a). Such an approach to the a priori has no commitment to a purely evidential theory of meaning or content. A theorist supporting this approach may reasonably remark that in 'Two Dogmas', the argument from holism of confirmation to the rejection of the applicability of any

(C) Blackwell Publishers Ltd. 2002 
interesting notion of the a priori proceeds so quickly because only purely evidential theories of meaning receive any serious consideration in that paper. Truthconditional approaches which are not purely evidential may be developed in a form which permits application of an interesting notion of the a priori, and the possibility of such treatments seems not to be addressed by the Quinean argument. The approach to the a priori which appeals to what is guaranteed by the possession conditions for the concepts composing a content can certainly be developed in the framework of a truth-conditional theory of meaning.

It would, however, be an extremely superficial reaction simply to note the gap in Quine's argument, and to leave the matter there. First, Quine presents a broad, general vision of the relations between meaning and rationality in the formation of beliefs. Any non-Quinean alternative must propose an equally broad and general vision, and defend its correctness. Simply saying that some contents and transitions are a priori, and that Quine's argument has a gap, is not meeting that need. Second, if a purely evidential theory of content is wrong, we need to know where and why it is wrong, and to draw on that knowledge in building a better general approach. Lastly, it cannot simply be that evidence is wholly irrelevant to meaning and content. In fact, for anyone who employs a notion of content constrained by Fregean consideration of cognitive significance, it is a consequence of the very nature of intentional content that evidence cannot be completely irrelevant. If, when we hold background information constant, there is something that is evidence for $p$ but not evidence for $q$, it follows that $p$ and $q$ are distinct Thoughts. If we apply Frege's classical test, someone with that evidence could rationally believe $p$ but not believe $q$. Even if they do not exhaust meaning, and even if they are not fundamental, evidential factors cannot be excluded from any epistemically significant notion of content.

\section{Evidence and Meaning: the Need for a Middle Way}

What then is the role of evidence in the individuation of concepts and meanings? On this issue, like so many others, we seem to need a middle way between two extremes.

At one extreme is the view that evidence has no part at all to play in the individuation of concepts and meanings, that is, has no part to play in the individuation of senses or intentional contents. Though this view certainly exists in the recent literature, it is too strong. We have already given an argument of principle against this extreme at the end of the preceding section. Its implausibility can also be illustrated by examples. There certainly seems to be a wide range of concepts for which certain evidential relations are constitutive or individuative. I list briefly a few. Having a perception of a desk straight ahead of one seems to give grounds, in everyday circumstances, for the content 'that desk is straight ahead', and that it does so seems to be partially constitutive of the identity of the concepts in the content. The same holds more generally for perceptual experience in relation to observational contents and concepts; for certain forms of premise as

(c) Blackwell Publishers Ltd. 2002 
constitutive grounds for certain contents containing logical concepts; for certain kinds of sensations as grounds for the self-ascription of a sensation of that kind; and so forth.

At the opposite extreme lies the Quinean view that meaning is not merely partially, but is exclusively, a matter of certain evidential relations. Despite many other changes in his views over the years, this purely evidential view of meaning is one that Quine held at the time of 'Two Dogmas', and through his later writings. Here are two statements from The Roots of Reference, twenty-four years after 'Two Dogmas' was first delivered:

The two roles of observations, their role in the support of theory and their role in the learning of language, are inseparable. Observations are relevant as evidence for the support of theory because of those very associations, between observable events and theoretical vocabulary, whereby we learn the theoretical vocabulary in the first place. (Quine 1974: 38).

Most sentences do not admit separately of observational evidence. Sentences interlock. An observation may refute some chunk of theory comprising a cluster of sentences, and still leave us free to choose which of the component sentences to count as true and which to abandon. The evidence relation is thus intricate and indirect. The same, of course, is true of the semantical relation. The semantical relation of observation to the theoretical language is similarly intricate and indirect, since we learn the language only partly by associating terms or sentence directly with observation, and partly by linking them to one another. The evidence relation, in all its intricacy, and the semantical relation, are coextensive still. (ibid.)

Yet it is highly problematic to suppose that meaning can be exclusively individuated in terms of evidence. (The same will apply to attempts at joint individuation in terms of consequences and evidence: the arguments I will offer below apply equally to such a mixed position.) I distinguish three interrelated problems for such an extreme, exclusively evidentialist, view. These are not the only problems, but they are problems that can be formulated without commitment to any heavy-duty competing philosophical theory. The problems can even be stated without explicitly mentioning the possibility of verification-transcendent truth, something which has always been an challenge for evidential theories of meaning. It is however, plausible that the possibility of verification-transcendent truth has its source in the conception which the problems illustrate. In any case, the problems I will be raising for purely evidential views all seem to me to be ones that do not arise for a properly-defended truth-conditional conception of meaning. The three problems can be described respectively as the problem of the informativeness of evidential relations; the problem of the source of evidential relations; and the problem of the insufficiency and parasitism of evidential relations.

(C) Blackwell Publishers Ltd. 2002 


\section{Problem (i), the Informativeness of Evidential Rrelations}

A thinker can often understand a sentence, or grasp a content, before knowing what would be evidence for it, or what consequences it would have, in the circumstances in which he finds himself. The thinker has, in short, to work out what would be evidence for the content. Contrary to Quine's assertion, such evidential relations cannot be the means 'whereby we learn the theoretical vocabulary in the first place'. Sometimes we have already fully learned the theoretical vocabulary when we are engaged in such working-out of what would be evidence for its application.

This point applies to many different kinds of content. It applies to hypotheses about currently unperceived, but perceivable objects. I may have to think about what would be evidence that my friend is spending today in Boston. It applies at the more elevated level of hypotheses the about behaviour of theoretically postulated entities in relation to observables; and to hypotheses about one level of theoretically postulated entities in relation to another level. How might the properties of a newly postulated form of matter affect radio waves reaching earth? To answer this question may be a major intellectual achievement. The concepts of the new kind of matter, of radio waves and of earth may be employed long before anyone has worked out the answer to it.

Could the proposed evidential sensitivity be captured by saying that it is sensitivity to evidence that there is a new form of matter with certain properties, without specifying what that evidence is? If this is supposed to be how the person who understands statements about the postulated new kind of matter thinks of the evidence, it is a way of thinking which clearly presupposes grasp of the hypothesis there is such a new kind of matter, and cannot be used to explain philosophically what is involved in that grasp. If it is not supposed to be how the person thinks of the evidence, it is not an evidential sensitivity which is constitutive of understanding. In the sense of evidence on which someone can have evidence that there is a new form of matter without necessarily thinking of it as such evidence, the evidence in that sense can be staring someone in the face, without his realizing that it is such evidence. A thinker's failure to recognize it as such does not impugn his understanding of sentences saying that there is a new form of matter with certain properties.

\section{Problem (ii), the Source of Eevidential Relations}

It is a real question how these evidential patterns allegedly constitutive of the semantical properties of a large set of sentences are, or even could be, worked out on Quine's account. What are they worked out from? It is surely what they are worked out from that should be mentioned in the account of understanding and meaning.

There are infinitely many sets of sentences large enough to have experiential confirming or refuting conditions associated with them. Our minds are finite.

(c) Blackwell Publishers Ltd. 2002 
How then do we grasp this association of evidential conditions with infinitely many sets of sentences? The association must be determined from some finite, graspable basis. What could that be? The association cannot, on Quine's view, be determined by the meanings of the individual sentences in the sets, and in turn from their finitely many components. Quine's thesis is that the sentences do not have meanings considered one-by-one.

This point applies however we conceive of the notion of evidence. It applies whether the evidential theorist favours sensory stimulations, perceptual experiences, or known truths about observable objects and events. The problem results from the evidential theory of meaning, together with the thesis that the assignments of evidential conditions are made only to large sets of sentences. This structural problem will then be present whatever our conception of evidence. In my judgement, when there is such an association of confirming or refuting conditions with a set of sentences, it is determined by the members of the set, which are themselves built up from finitely many constituents.

Why has this problem, that a Quinean style of evidentialism is committed to understanding involving an association that is, by the lights of his theory, not finitely graspable, not been more generally recognized? I think there has sometimes been a failure to distinguish between what I will call radical evidentialism and structured evidentialism. In his well-known discussion 'The Significance of Quine's Indeterminacy Thesis', Michael Dummett (1978) considers the model of meaning found in the later sections of 'Two Dogmas' and in Quine's later writings. Dummett says that under the model of 'Two Dogmas', some individuation of the meaning of an individual sentence is still possible. In the case of a nonobservational sentence - $\mathrm{a}$ 'non-peripheral' sentence in Quine's image of the web - our understanding "consists in our knowledge that it can be established or refuted only by means of an inference of a certain kind. The sentences to which a non-peripheral sentence is directly linked will, in general, be further nonperipheral sentences, which will, in their turn, be linked with yet other sentences. In general, there will be a large number of different possible paths leading, by means of such links, from the periphery to any non-peripheral sentence, any such path representing the total process of verification or falsification of that sentence" (p. 81). That is a formulation of what we can call structured evidentialism.

It is not surprising that, if structured evidentialism is attributed to Quine, there is a severe problem - precisely the one Dummett identifies - of seeing how Quine can believe in the Thesis of the Indeterminacy of Translation. The translation of one sentence by another is correct if and only if the two sentences have meanings that are individuated by the same tree structures of possible paths of verification or falsification, and that they are so is subject to no more than normal inductive uncertainty. This prima facie incompatibility of structured evidentialism with the Indeterminacy Thesis should already make one suspect that Quine holds something different; and I think he does. Quine holds radical evidentialism, which states that the best we can do by way of giving meanings is to specify a meaning for a large set of sentences, and we do that by associating that set with evidential

(C) Blackwell Publishers Ltd. 2002 
conditions. It is not that there is nothing to be said about how those evidential conditions are derived. There are associations between theoretical sentences and other theoretical sentences; and between theoretical and observational sentences. But these are, according to the radical evidentialist, simply non-constitutive means by which sets of sentences come to have some association with observational conditions. Any sentence other than an observational sentence simply features in a huge number of large sets to which confirming conditions are assigned. There is no case in which, for a non-observational sentence, it is assigned confirming conditions or inferential patterns or tree structures by itself. The radical evidentialist will not deny that there are tree structures representing possible paths of confirmation of the sort Dummett describes. The radical evidentialist just denies that they are individuative of meaning: those tree-structures themselves depend upon auxiliary hypotheses. According to the radical evidentialist, meaning must be a matter of some relation, however complex, in which the sentence stands to observation or the favoured kind of evidence itself. For the radical evidentialist, complexity of association of evidential conditions with linguistic items is to be captured not by associating more complex entities as the meanings, such as constitutive inference patterns, but by associating evidence of the favoured kind with more complex entities, large sets of sentences or even theories.

There are, besides his endorsement of the Indeterminacy Thesis, other strands in Quine that suggests that he holds radical evidentialism. When Quine writes, 'the evidence relation ... and the semantical relation of observation to theory' are coextensive, even after we take into account all the intricacies of confirmation of whole sets of sentences, that certainly seems to imply: same confirming and refuting observations or evidence, same meaning.

Dummett's structured evidentialism may seem much more intuitive and more respectful than radical evidentialism of the nature of the meanings of nonobservational sentences. Certainly structured evidentialism can avoid infinitary associations of evidential conditions. Canonical inferences patterns which individuate a non-peripheral expression are associated with linguistic items one-by-one. The meaning of a complete sentence can be determined by the meaning of its constituents under structured evidentialism. But structured evidentialism still faces a challenge about the association of evidential conditions with complete sentences. The intuitive point that we can often understand an individual sentence without knowing what, in our actual circumstances, would be evidence for it, is one to which a structured evidentialist must equally respond. It cannot be correct to write into a Dummettian structured individuation of the meaning of a hypothesis those evidential relations that can be discovered only after hard thought, and after possibly years of understanding the hypothesis in question. I will be arguing soon that the correct explanation of this phenomenon - of the possibility of understanding of a sort that does not consist in, but allows one, if one is smart and lucky enough, to work out evidential conditions - is an explanation that is incompatible with purely evidential theories of meaning. It has deep realistic roots.

(C) Blackwell Publishers Ltd. 2002 


\section{Problem (iii), the Insufficiency and Parasitism of Evidential Relations}

Even in cases in which experience plays a role in understanding, as it does in observational concepts of the perceptible world, understanding also involves more. It involves showing in one's thought some appreciation of the possibility that the property of an object that in fact causes one's perception is a property which could be instantiated unperceived by oneself or by anyone else. To have this appreciation is to have some tacit conception of the observed property as something categorical. The categorical cannot be reduced to the holding of counterfactuals. ${ }^{6}$ It is because a property is categorical that it is capable of featuring in causal explanations, in particular explanations of the thinker's and of others' perceptions.

Now what would be experiential evidence, or any other kind of evidence, that this same property as one perceives is instantiated at other places and times is something which has to be worked out. It is very much an empirical matter. It is the notion of a categorical property that forms the constitutive bridge between the perceived and unperceived cases. What makes something, in the context of other information, evidence that some property picked out by an observational concept is instantiated unperceived by the thinker? I suggest that what makes it so is that it is evidence that the same categorical property as is perceived to be instantiated in the perceived cases is instantiated also in the cases which the thinker does not perceive the object in question. ${ }^{7}$ I contend that this condition, formulated in terms of sameness of property and the metaphysics of the categorical, cannot be framed in terms of a purely evidential theory of meaning - or not in any way that is not parasitic on non-evidential matters.

Perhaps it may be said that this problem would not arise if an evidential theory of meaning were cast in terms of propositions about the objective perceptible world itself, instead of experience. Fair enough. But grasping such evidential conditions would itself then already involve some tacit appreciation of properties as categorical. For such a variant of evidentialism, problem (i), of the informativeness of evidential relations, would also rearise yet again in the case of the relation between such evidence and theoretical notions. When a theorist has the idea that some particles' orbits are arranged in such-and-such shapes, what would be evidence for this again has to be worked out empirically. The understanding of the hypothesis involves a notion of shape as a categorical property.

\section{A Generalized Rationalism}

I turn now to sketch the outlines of an alternative conception of the system of relations between meaning, the a priori and rationality. Quine's radical holism was forged in reaction against Carnap's conception of meaning and its consequent account of the source of experience-independent justification. The alternative I have to offer is emphatically not a variant of a Carnapian approach. The alternative I

(C) Blackwell Publishers Ltd. 2002 
propose is rather an elaboration and generalization, in several respects, of the classical rationalist tradition present in different forms in Leibniz, Frege, and some parts of Gödel. This generalized rationalism diverges from Carnap on many issues. It diverges not only on the matter, already mentioned, of whether the notion of truth-purely-in-virtue of meaning has any application. It diverges also on whether there are conventionalist elements in the acceptance of a priori principles, and on whether there is a substantial form of relativity to a language or to a framework in the acceptance of a priori principles. I will characterize this rationalist alternative by formulating three principles, and offering some brief considerations in support of each. Converting the sketch into a detailed picture would be a task for some years' work. Here I offer just a sketch that identifies the main elements of the position, their relations to one another, and some rationales for seeing the situation this way.

The position to be sketched will be available at least to some truth-conditional theorists of meaning. This was prefigured in the remarks against exclusively evidential accounts of meaning. The treatment I endorsed of the meaning of observational statements may be seen as an elaboration of a truth-conditional treatment thereof, with the implicit grasp of the notion of the categorical contributing to the substantive - not necessarily reductive - account of what is involved in grasping truth-conditions of observational statements. (I should add, however, that not all truth-conditional theorists of meaning will accept my sketch of a rationalist alternative. It will not be acceptable to those who hold that no variant of the notion of sense or meaning, going beyond the level of reference, is intelligible.)

On a truth-conditional conception, the phenomenon of the informativeness of evidential relations, and of the finiteness of the source of evidential relations, are both explicable. It is the truth-conditions which can be grasped in advance of working out what can be evidence for a content. A thinker draws on his grasp of those truth-conditions in working out, in the context of additional information, what would be evidence for the truth of a content. Truth-conditions are also componentially determined: the truth-conditions of a complex sentence are fixed by the mode of composition of its constituent expressions, together with the senses of the individual expressions composing the sentence. The finite basis for grasp of the truth-conditions of whole sentences can then also serve to provide, in the presence of additional empirical information, a finitely-based source of evidential relations. As always, these claims are made in context of the assumption that there is a substantive theory, for each particular sense, of what it is to grasp that sense, a theory which also explains the conditions for the sense to have a given reference.

The criticisms I gave above of Quine's evidential theory of meaning are also further grist to the mill of those who, like Davidson, want to free the theory of meaning and understanding of any scheme/content distinction. ${ }^{8}$ All the preceding considerations tell against the idea that meaning or intentional content is just a way of organizing experience or evidence.

The three rationalist principles that I am going to present are framed as claims

(c) Blackwell Publishers Ltd. 2002 
about the relation of entitlement. I follow Burge in according this notion a central place in epistemology and the theory of meaning and content. ${ }^{9} \mathrm{~A}$ transition to which a thinker is entitled is a rational transition. A judgement is knowledge only if it is reached by transition to which the judger is entitled. A thinker may be entitled to make a judgement without having the capacity to think about the states which entitle him to make the judgement: a child may be entitled to make an observational judgement by his perceptual experience without his having the concept of perceptual states. Examples of transitions to which a thinker is entitled include the following: making logical inferences; basing observational judgements on perception; self-ascribing sensations when experiencing the sensations; taking memory at face value in specified circumstances. This is just a selection. The transitions which we divide into those to which the thinker is entitled and those to which he is not could be given a canonical notation, along the lines of Goldman's 'cognitive state transitions' or Nozick's 'methods'. ${ }^{10}$ The notion of entitlement is meant to be an articulation of a concept we already employ in ordinary non-philosophical epistemic assessment, in assessing a subject's beliefs as rational. I do not mean to imply that knowledge can be reductively elucidated in terms of entitlement and other notions. My own view is that there is a large circle of interrelated notions, including entitlement, knowledge and even intentional content itself, each of whose elucidations ultimately involves the others. ${ }^{11}$ For those who doubt that there is any notion of entitlement having all of these properties, I ask them to take it as part of the present theory that there is such a notion, and to assess the total theory which has this claim as a part.

The first principle I have to offer as part of a rationalist conception is one that is not unique to rationalism, though it is also certainly not universally held:

\section{PRINCIPLE I: The Special Truth-Conduciveness Thesis}

A transition is one to which a thinker is entitled only if the transition tends to lead to true judgements (or, in case the transition relies on premises, tends to do so when its premises are true), in the way characteristic of rational transitions.

I will call the property here suggested as a necessary condition for a transition to be one to which the thinker is entitled the property of being rationally truthconducive'. All the examples of the relation of entitlement that I gave are intuitively rationally-truth conducive. What it is that is characteristic of rational transitions must wait till discussion of the next Principle.

The property of a transition of tending to lead to true judgements (or to do so when its premises are true) is not by itself enough to make a transition entitling. Pure reliability of a transition is not by itself enough to make the transition entitling, as, in my judgement, many examples in the discussion of pure reliabilism over the years have shown. ${ }^{12}$ If I am wrong about this, and there is a form of pure reliabilism that can capture a rationality requirement, all well and good. Were there to be such a form of reliabilism, I am in agreement with a theorist who

(c) Blackwell Publishers Ltd. 2002 
endorses it in holding that in the relevant cases of reliability, rationality requirements for entitlement will be fulfilled. Such a theorist and I are both in disagreement with a third party who holds both that reliability is all that is needed for entitlement, and that it does not involve rationality at all. Principle I is then, opposed to what is sometimes called 'externalism' about justification in epistemology. I will later be arguing, however, that the right way of developing a rationalist conception involves acceptance of externalism in the theory of intentional content. ${ }^{13}$

Thinkers are entitled, prima face, to take the content of their perceptual experiences at face value. But it seems that there could be a Cartesian evil demon ensuring that the contents of all of one's perceptual experiences about the external world are false. Taking perceptual experience at face value will not lead to true belief in such an evil-demon world. How then can we include amongst the transitions to which one is entitled the transition from a perceptual experience to the correctness of some content it rationalizes?

The transition is required to be truth-preserving only in worlds of a kind which one has a prima face, defeasible entitlement to believe one is in. For this reply to be more than an empty box, one must have some systematic and general account both of what one is entitled to presume, defeasibly, about one's circumstances, and of why one is entitled to presume it. I return to this crux below.

The intuitive attractions of Principle I lie in the internal relations between rationality, truth and the aim of judgement. It is a constitutive aim of judgement that one tries to judge that $p$ only if it is true that $p$. Rational ways of coming to make judgements must be ones that tend to lead to the truth.

Principle I is meant to state a substantive, non-trivial constraint on the entitlement relation. It would not be a substantive constraint - indeed it would result from legitimate substitution in a logical truth - if truth itself had to be explained in terms of a certain kind of entitlement or reasonableness. It is part of the modern rationalism I am advocating that no such explanation is possible. But the claim is certainly controversial. One kind of pure conceptual-role or inferentialist theory would say that truth and reference do not have any essential role to play in an account of reasons and rationality. Robert Brandom describes a group of theorists, of which he himself is one, who 'start with a notion of content as determining what is a reason for what, and understand truth and representation as features of ideas that are not only manifested in but actually consist in their role in reasoning $^{\prime}{ }^{14}$ So we need to ask the question: can we elucidate the rationality of a transition without alluding to truth and reference?

I suggest three reasons why we cannot (this paper seems committed to the German maxim that all good things come in threes). The first reason I label 'the Adequacy Problem'. Any pure conceptual-role theory or inferentialist theory has to answer the following question, a question to be faced by every account of rationality: is its account of rationality consistent with the fact that judgement aims at truth? Truth is certainly not the sole aim of judgement. But a mental relation to a content $p$ is judgement that $p$ only if the thinker aims to make it this the case: that he stands in that relation to $p$ only if it is the case that $p$. In the case of pure concep-

(c) Blackwell Publishers Ltd. 2002 
tual-role theories (within which I will henceforth include inferentialist theories), the more specific form this question takes is: why should judging in accordance with certain specified roles tend to produce true judgements? This is the Adequacy Problem for pure conceptual-role theories.

A direct answer from these theorists to the Adequacy Problem would be to say 'For a content to be true is for it either to be establishable by specified conceptual roles, or to have all of its consequences, under specified conceptual roles, to be establishable' ${ }^{15}$ This characterization of truth is, however, very heavily anti-realistic. It requires that in every case in which a past-tense content is true, we can either establish it, or it has consequences all of which are establishable. There is, intuitively, no problem with the idea of a past-tense truth that has no present traces, and hence no consequences, at all. I would argue that this is a consequence of a proper understanding of the objectivity of past-tense statements, as saying the same about the past as their present-tense counterparts. ${ }^{16}$ Such a possibility of verification-transcendent truth for empirical statements about the past is not excisable without cutting out too much of what is involved in objectivity.

Alternatively, the pure conceptual role theorist may say that for a past-tense statement to be true is for to have been establishable at the relevant time in the past, by someone suitably situated. It can be true that it was verifiable, consistently with there not being, either now or in the future, any traces at all that this was so. I suggest, however, that for reasons that should by now be familiar, this account is either circular or inadequate. The problem arises from the case of pasttense truths that would not have held had an observer been present. The account of the truth of a past-tense content $p$ in terms of what would have been establishable in the past is an account that works only if we add the qualification that the presence of the establishing thinker would not have affected whether $p$ was the case. But far from explaining content in terms of establishability, this account presupposes some prior explanation of what it is for $p$ to be the case, and to be unaffected by the presence of the establishing subject. If we do not add the qualification, the account gives the wrong truth-conditions in the case in which the presence of the observer does affect whether $p$ was the case. ${ }^{17}$

Yet another response to the Adequacy Problem might be revised to say that truth is a property that sometimes holds when there is some kind of canonical establishability, or establishability of each canonical consequence, but which also holds in some other cases. That is surely correct; but I doubt that we can say what captures these other cases unless we use notions of truth and reference which do not consist wholly in their role in reasoning. Intuitively these other cases of truth should be captured by the condition that in them too, for example, an object really - but unestablishably - has at the specified time the same property it is established as having when it does hold establishably. This is then an explication of truth and reference which does not consist wholly in citing roles in reasoning. This explication uses a substantial notion of truth, and of reference to individuals and to properties, precisely in order to elucidate features of truth which are not explicable solely in terms of reasoning. ${ }^{18}$

A different response to the Adequacy Problem, a response intended to avoid

(C) Blackwell Publishers Ltd. 2002 
both the problems of the most recent proposal, and to avoid a commitment to anti-realism, is to insist that establishability by canonical conceptual roles is at least a sufficient condition for truth (even if it is not a necessary condition). Could this be used by a pure conceptual role theorist as a starting point for reconciling his position with the fact that judgement aims at truth? It seems to me to move the bump in the carpet to another corner. How are the contents recognized by this theorist ones which can in some cases hold unestablishably? If none of them can ever hold unestablishably, anti-realism has not been avoided. If some of them can, the question remains of how truth and reference can be explained solely in terms of their role in reasoning.

The second problem I want to raise for accounts of rationality and reasons that make no essential reference to truth is given by the question of which sets of roles and principles determine genuine concepts or meanings. Not every set of roles or rules determines a meaning or concept. I would say that a set of rules determines a genuine meaning only if there is a semantic value for which they are all truthpreserving. If this is so, then it is a mistake to think of rules as a means of explaining entitlement that does not involve truth. The conditions for a set of rules to be legitimate can be given only in terms of semantic value (reference) and truth.

The rival view of conceptual-role theorists, and some of their allies, is that the conditions for the legitimacy of a rule as fixing a meaning can be given in terms of a Conservative Extension requirement. Suppose we have a theory $\mathrm{T}$ formulated in a language not containing the expression N. Suppose we have a new rule $\mathrm{R}$ which contains the new expression $\mathrm{N}$. The rule $\mathrm{R}$ is said to be conservative on $T$ iff: for any set $S$ of sentences not containing $N$, and any particular sentence $A$ not containing $\mathrm{N}, \mathrm{A}$ is derivable from $\mathrm{S}$ in $\mathrm{T}+\mathrm{R}$ only if it is already derivable from $\mathrm{S}$ in $\mathrm{T}$. That is, the new rule does not extend the relation of derivability-in-T on sentences formulated in the old, unextended language. The Conservative Extension requirement is endorsed in various forms by Nuel Belnap, Michael Dummett and (with additional qualifications) Robert Brandom. ${ }^{19}$

This is not the place for a detailed discussion of the issues in the literature, which was initiated by Prior's famous note on 'tonk'. ${ }^{20}$ In summary, my view is that Conservative Extension is both too strong and too weak to rule out the undesirable cases. It is also the wrong requirement as a matter of principle for realists. It is too weak, because there are examples in the literature of spurious operators, the rules for which do not violate Conservative Extension. We can imagine a spurious operator vel which has the same introduction rules as classical alternation, has some arbitrarily restricted elimination rule (for instance, to premises less than a certain length), and for which these are said to be the totality of valid rules. These rules are conservative over any theory, since they are a subset of the rules for classical alternation. But I do not think we know what vel means. A vel B cannot mean 'A or B or $p$ ', for some condition $p$, or else additional introduction rules would be valid for it. But it cannot mean something as strong as 'A or B', for then the elimination rule would be unrestricted. Though vel has a specified consistent and conservative set of rules, I suggest that we do not know what it means. $^{21}$

(c) Blackwell Publishers Ltd. 2002 
Conservative Extension is also too strong as a requirement for a set of rules to be meaning-determining, because there are clear violations of Conservative Extension which are positively desirable. Adding second-order quantifiers to a language for first-order arithmetic can allow one to prove the Gödel sentence for the unextended language and theory not containing second-order quantifiers. This is not fallacious, and it certainly does not involve a 'change of meaning' of the vocabulary used in proving the Gödel sentence. Nor is this a case of an empirical theory that non-conservatively extends some prior theory. Second-order arithmetic is not an empirical theory.

Some pure conceptual-role theorists and inferentialists assert that violations of Conservative Extension must involve a change of meaning. I reply that this could be so only if the meaning of an expression in the unextended language is completely exhausted by the methods of proving certain sentences containing it, and of proving certain consequences from it, in the unextended language and theory. If a sentence in the unextended language is newly provable after the introduction of some new vocabulary, and rules for it, that is a positively desirable state of affairs provided the sentence was already true under its meaning in the unextended language. That is the case for the Gödel sentence for first-order arithmetic. Violations of Conservative Extension, a proof-theoretic notion, are unobjectionable as long as they are semantically conservative in that sense. But semantic conservativeness is a notion that immediately involves truth. One cannot characterize the boundaries of legitimate rules without relying essentially on the notion of truth.

This second reason for saying that rationality cannot be elucidated independently of reference and truth also tells against those pure conceptual role theorists who say that only warranted assertibility, and not truth, is the aim of judgement. What I have argued equally implies that the roles that determine genuine warrant cannot be picked out unless we rely on reference and truth. Even if mere warranted assertibility were the aim of judgement, we would still need to say which sets of rules determine genuine meanings and which do not. Unless this theorist has some new resource for ruling out spurious meanings, he will need to rely on considerations having to do with reference, semantic value and truth; and then his conceptual role theory is no longer pure.

The third, and in some ways the most fundamental reason that we cannot elucidate rationality without mention of truth and reference can be argued once it is granted that truth and reference cannot be explained in terms of reasons and entitlement. Truth is the aim of judgement of a content; truth depends on properties of the objects (and other entities) mentioned in the content; so rationality in judgement must be a matter of some complex relation of the content judged to properties and relations of the objects and other entities that are the subjectmatter, at the level of reference, of the content judged.

The point can be illustrated at the most basic level of conceptual thought. It seems to me very implausible that one can explain why one is entitled to make judgements in accordance with basic conceptual roles for perceptual-demonstratives, or for recognitional concepts, without alluding to the fact that these are

(C) Blackwell Publishers Ltd. 2002 
rational ways of finding out about the objects that are given in perception. Nor, it seems to me, could the full conceptual role be properly characterized without taking into account the conditions under which they refer to particular objects. Under what conditions am I entitled to judge "That chair [perceptual-demonstrative] is $\mathrm{F}^{\prime}$ when that chair is not actually presented to me in perception as being F? If I know, for instance, that that chair is the one I carried in from the corridor, and know this by having kept track of it, I am entitled to judge 'That chair is the one I brought in from the corridor', even though that information is not given in my current perceptual state. There seems to me no plausible way of characterizing the conditions for such entitlement except in terms of the thinker's information about the object picked out by the perceptual-demonstrative - that is, by its reference, and thus by the contribution it makes to truth-conditions.

So much by way of an overview of the considerations in support of Principle I, the Special Truth-Conduciveness Thesis. Each of these considerations, in its own way, implicates a role for a substantial notion of truth and reference in the explication of rationality. Principle I is not by itself however exclusively and distinctively a rationalist principle, even though it is part of a rationalist conception. Principle I could be endorsed by a theorist who holds a purely reliabilist view of why some truth-conducive methods are entitling. The next two Principles I want to articulate are, however, distinctively rationalist.

\section{PRINCIPLE II: The Rationalist Dependence Thesis}

The rational truth-conduciveness of any given transition to which a thinker is entitled is to be philosophically explained in terms of the nature of the intentional contents and states involved in the transition.

This Principle, in speaking of any transition to which a thinker is entitled, goes vastly beyond what was discussed by the classical rationalists, whose concern was usually with the outright a priori. But I want to consider first what the classical rationalists held about transitions to which we are entitled independently of the content or kind of perceptual experience; and then to consider whether some generalization is possible, once we appreciate the conception they were expressing.

The claim that there is a dependence of the rationality of accepting certain principles upon the identity of the concepts they contain, and thereby a connection with understanding, is present in progressively more explicit forms in Leibniz, Frege and Gödel. It is important to characterize the nature of the rationalist conception correctly. It is quite insufficient to say that a rationalist view is one that holds that there are a priori principles, and holds that this a priori status is founded in the nature of the concepts in the principles, and is available to anyone who possesses those concepts, or properly understands the expressions in the principles. As Quassim Cassam notes, conventionalists such as Carnap (1937) and the Ayer of Language, Truth and Logic (1946) meet that description. ${ }^{22}$ Consider a conventionalist who holds this combination of views: any (consistent) set of prin-

(c) Blackwell Publishers Ltd. 2002 
ciples determines a concept; to possess the concept is to know those principles for the concept; and the experience-independent truth of those principles involves no more than their conventional acceptance of those principles. A conventionalist holding this combination acknowledges the a priori status of certain principles, and also founds this status in concept-identity, and connects knowledge of the principles with understanding. But this is quite outside the spirit of a rationalist position. ${ }^{23}$

What distinguishes a rationalist position is not merely its acknowledgement of a priori principles, and some link between that phenomenon on the one hand and concepts and understanding on the other. A rationalist holds that what it is for one of these principles to be true is not to be explained in conventionalist terms, but involves the application of a uniform notion of truth applicable to arbitrary contents. A rationalist holds that understanding consists in grasp of truth-conditions, given by applying this uniform notion of truth. A rationalist holds further that these principles are knowable through the use of reason - though of course rationalists may differ greatly on how such knowledge is possible, and what it involves. Leibniz emphasized that some principles to which we are entitled independently of the detailed content of perceptual experience are accessible by the use of reason. It would be anachronistic to attribute a systematic referential semantics to Leibniz. Nonetheless, it is clear that according to him, in a huge range of cases such principles can be traced back to the law of identity, or to what we now call Leibniz' Law. ${ }^{24}$ The principle that $\mathrm{A}=\mathrm{A}$, and Leibniz' Law itself, are principles which are implausible candidates for a conventionalist treatment. Frege's treatment of the laws of his formal system in Grundgesetze is squarely rationalist in the sense I have been emphasizing. He aimed to give a justification of each of the laws of his logical system, from principles about the reference of the expressions they contain. Consider Frege's Law I, which is $(\mathrm{A} \supset(\mathrm{B} \supset \mathrm{A}))$ in modern notation. The statement of this law in Frege's text is immediately preceded by the German word 'also', meaning 'therefore'; and what precedes the 'also' is an argument from the truth-functional semantics for the conditional that Frege had given earlier, in section 12, to the impossibility of this law ever having the truth-value False (or denoting it, in the theory of that book). ${ }^{25}$ Though Frege's philosophical writings in places endorse what certainly looks like a redundancy theory of truth, his actual practice in the Grundgesetze, which was meant to be an implementation of the project of tracing the laws of arithmetic back to their 'ultimate justification', gives a theory of reference and truth a much more substantial role. In the case of Gödel, no one who has read his philosophical writings, and in particular the several versions of the explicitly anti-Carnapian 'Is mathematics syntax of language?", could be left in any doubt as to his opposition to any form of conventionalist treatment of logic and mathematics. ${ }^{26}$

What of the transitions in the scope of Principle II that go far beyond those considered by the classical rationalists? If we are to retain the core of a rationalist conception, we need to generalize along two related dimensions. First, we need to consider all those rational transitions which are not cases of logical or mathematical inference. There is a huge range of types of such transition, including

(C) Blackwell Publishers Ltd. 2002 
transitions to judgements about the state of the external world; transitions to judgements about one's own mental states; transitions to judgements about others' mental states; and so forth. In the case of transitions to judgements about the external world, many such transitions will involve moving from the content of some representational state, such as perception or memory, to the judgement of a content made rational by that state, when one is taking it at face value. Second, since such transitions can lead to rational judgements only if it is rational to take the state with the representational content at face value, one must also have an explanation of why it is rational to take the relevant states at face value. Principle II implies both that the rationality of the transition, and the rationality of taking the state at face value, are to be explained philosophically in terms of the nature of the intentional contents and states involved in the transition. The twin tasks of explaining in convincing detail the rationality of these transitions, and the rationality of outright reliance on states of a given kind, within the announced constraints of Principle II, are major items on the agenda for a modern, generalized rationalism.

The first of the two tasks, that of explaining the rationality of the transitions, takes a particular form for those who believe in the nonconceptual representational content of the states which are taken at face value. For such theorists (I am one of them), the task is to show this: in each case in which the nonconceptual content of a state entitles the thinker to make a corresponding judgement, the correctness of the nonconceptual content implies the correctness of the conceptual content to which the thinker is thereby entitled (when he is entitled to take perceptual experience at face value). There are efforts in this direction in the literature. ${ }^{27}$ The correctness of the judged content, given that of the perceptual content, must not rely on other empirical information: otherwise the transition would not be rational, if it is based on perception alone. It would be a leap in the dark. In other words, the correctness of the judged content must be a relatively a priori matter relative to the correctness of the content of the perception. The transition itself has an a priori character.

The case of the entitlement to rely on various informational states is complex and fascinating, and here I can only outline a position that seems to me to be available to a contemporary generalized rationalism. Let us for the moment restrict our attention to perceptual states, and the entitlement to take their observational content at face value. I suggest that the external individuation of the intentional content of such states is crucial for the existence of an entitlement to take them at face value. ${ }^{28}$

Consider the spatial and temporal representational content of a perceptual state. What makes it the case that the perceiver's impressions are impressions as of spatial and temporal properties and relations? What makes it so are the complex relations in which states with such contents stand to instances of the spatial and temporal properties and relations themselves, in the basic case in which we have a subject properly embedded in the world in the way that we take for granted in propositional-attitude explanation and ascription. The complex relations in question include the explanation of significant examples of the spatial

(c) Blackwell Publishers Ltd. 2002 
and temporal impressions by instances of the spatial and temporal properties and relations of which they are impressions. Certainly, some temporal and spatial impressions reliably misrepresent, even in standard circumstances. Still, their content is dependent upon their relations to others that do not so misrepresent.

A thinker who is in a perceptual state with a given representational content is entitled to accept that he is in the circumstances with respect to which those contents are individuated, in the absence of any reasons for doubting it. In those circumstances, the intentional contents of his perceptual states do, on the whole, bear those complex relations to what they represent that are individuative of the contents. Thus the thinker is prima facie entitled to take such contents of perceptual experience at face value.

These points about the individuation of perceptual contents do not of course need to feature in the thought of the perceiver. Rather, this is a first step towards a philosophical account of the conditions under which a non-inferential entitlement exists.

It is an attraction of this approach that it explains why various states that are merely inferentially entitling fall short of being non-inferentially entitling. Berkeley held the view that a subject can tell by looking when one object is farther away from her than another because the more distant one is will have a more bluish hue. Even if this account were extensionally correct, which it is not, an increasing blueness as objects are further away can give only inferential, and not non-inferential, entitlement for the judgement that one object is farther away than another. It can give only inferential grounds precisely because the content involving blueness is not individuated by anything to do with distance. In this, it differs from the genuinely spatial intentional content involved in the experience of actually seeing one thing as being farther away from oneself than a second thing.

The prima facie entitlement to take the observational content of perceptual experience at face value must itself be a priori. If it were a posteriori, it would have to rest on other empirical propositions to which the thinker is entitled and how could such entitlement exist, except as a result of other informational states the thinker is entitled to take at face value? Moreover, the outline of an argument that there is such an entitlement seems to me to be itself a priori. It is a philosophical argument, not clearly relying on any particular empirical propositions.

It remains a task to explain why this link between external individuation of certain perceptual contents and entitlement should exist. It is one thing to identify a true generalization, another to explain why it holds. The explanation must relate the generalization to rational truth-conduciveness. If it is not to import elements of pure reliabilism, the explanation must not take it for granted that a normal world, or the actual world, is a certain way. Identifying such an explanation should be another item on the agenda of a contemporary Generalized Rationalism. ${ }^{29}$

If this style of approach is along the right lines at all, it suggests a third principle:

(C) Blackwell Publishers Ltd. 2002 


\title{
PRINCIPLE III: The Generalized Rationalist Thesis
}

The kind of explanation of rational truth-conduciveness in terms of content and states that underlies entitlement entails the following: all instances of the entitlement relation, both absolute and relative, are a priori.

In every case, it has seemed that the rationality of a transition, or of reliance on the informational content of a state, requires that there exist some ratification of an a priori kind that that transition is truth-preserving. It is a Corollary of Principle III that there are no irreducibly a posteriori instances of the entitlement relation. This is not, of course, to adopt the ridiculous view that nothing is a posteriori. Rather, any a posteriori entitlement is explicable in terms of instances of an entitlement relation all of whose instances have an a priori character. That is, in every case in which we have an entitlement that seems to be a posteriori, what we actually have is a case in which some parameter has been suppressed or ignored, and which when it is revealed unfolds the case into one in which all the fundamental entitlements are a priori. My entitlement to believe that if one place on a particular hill is higher than a second, the first is on average cooler, is certainly a posteriori. But relative to the perceptual evidence that supports it, the entitlement can still be a priori. In general, a priori but nonconclusive principles of support will be crucial in defending Principle III.

It is a major task to elaborate these three Principles of Rationalism in more convincing detail than has been possible in this sketch. The sketch is, however, intended to outline a non-Quinean conception of the relations between content, truth, rationality and the a priori that respects Quine's great, and in many respects decisive, criticisms of Carnap. What I have outlined should certainly not be seen as opposed to Quine on all points. To mention but one: Quine emphasized the pragmatic character of much belief revision, and it would be ostrich-like to deny the point. But even here I suggest that pragmatism operates within rational constraints: and those rational constraints are fundamentally a priori. ${ }^{30}$

\author{
Christopher Peacocke \\ Department of Philosophy \\ New York University \\ Main Building Room 503 \\ 100 Washington Square East \\ New York NY 10003-6688 \\ USA \\ cp4@nyu.edu
}

\section{NOTES}

1 Here I agree with Dummett and Rorty (a rare state for anyone): '. . the concluding third of Quine's article, which is the important part . .' (Dummett 1978: 375-6); ' "Two

(c) Blackwell Publishers Ltd. 2002 
Dogmas" ... exhibits great argumentative skill as well as great imaginative power. But the latter does most of the work.' (Rorty 2001: B9).

2 For further discussion of variant notions of the a priori, and their significance, see Peacocke 2003.

3 Both papers are reprinted in Quine 1976.

4 See Peacocke 1993a, Boghossian 1997.

5 In fairness to a possibly nonexistent class of theorists, one should add that even the reductionist empiricist who accepts Quine's second dogma need not be a friend of the idea that some sentences are true purely in virtue of meaning. This reductionist thinks that certain statements are true come what may, because they are confirmed by every sequence of experience-types that may be instantiated. He need not hold in addition that statements with this special property are 'true purely by virtue of meaning'. Quine believes that he still has an argument in 'Two Dogmas' against such a reductionist who also believes that some truths are a priori.

6 For a defence of this characterization and related claims, see the section entitled 'The Categorical', in my paper 'Understanding the Past Tense' (Peacocke 2001a: esp. 352-59).

7 This is why the verification-transcendent instantiations are not 'free standing', as Hilary Putnam (1995: 12) rightly insists they cannot be.

8 Davidson 2001 'On the Very Idea of a Conceptual Scheme'.

9 Burge 1993.

10 Goldman 1986: 77-8; Nozick 1981: 179-85.

11 Peacocke 1999: Chapter 2.

12 For support for this claim, see BonJour 1985, especially Chapter 3, 'Externalist Versions of Foundationalism'. For a contrary view, see Goldman 1986: 109-21.

13 The classic sources are Putnam 1975 and Burge 1979.

14 Brandom 2000: 47. Brandom calls such theorists 'post-Cartesian rationalists'. The discussion further below gives reasons for questioning whether historically rationalists have really had that attitude to truth.

15 This answer is drafted to take into account that conceptual-role theorists quite properly include certain canonical relations of consequence, as well as canonical grounds, in their individuation of content. See Dummett 1973: 453ff.; and Brandom 2000.

16 See Peacocke 1999: Chapter 3.

17 For further discussion, see Peacocke 1999: Chapter 3.

18 Under impure conceptual role theories, some specified conceptual role contributes to the individuation of a meaning or a concept, but there are also substantial constraints, formulated at the level of truth and reference, upon genuine meanings or concepts. Such theories have in principle the resources for meeting the Adequacy Problem; whether they succeed depends upon their details.

19 Op. cit.; and Belnap 1962.

20 Prior 1960.

21 For further discussion, see Peacocke 1998; and also the discussion of the spurious 'quantifier' Qx...x... in my 'Proof and Truth' (Peacocke 1993b).

22 Cassam 2000.

23 For related points on inadequate characterizations of the opposition between rationalism and empiricism, see further Cassam 2000.

24 See amongst many other passages, Leibniz 1981: Book IV, ‘Of Knowledge’, esp. Ch. vii 'Of Maxims or Axioms'. On his own use of Leibniz' Law, see for instance pp. 413-4 of this same chapter.

25 Frege 1998, Section 18, p. 34.

(C) Blackwell Publishers Ltd. 2002 
26 Gödel 1995.

27 See Peacocke 1992: Ch. 3 at pp.79-80; and the remarks on this enterprise in Peacocke 2001b. For those conceptualists, like John McDowell, who hold that the representational content of perception is conceptual, there is no substantial first task: the relevant part of the perceptual content, and the judgement it makes rational, are identical.

28 What I am arguing for here is what I call 'the Second Linking Thesis' in Peacocke 2001c, where there is a somewhat more detailed discussion of these points.

29 For further discussion and a proposal, see my 'Explaining Entitlement: The Perceptual Case', forthcoming.

30 This paper was presented in an invited Symposium at the 2001 meeting of the Eastern Division of the American Philosophical Association on the fiftieth anniversary of the publication of 'Two Dogmas of Empiricism'. My co-symposiasts were Michael Friedman and Richard Grandy. I have been helped by their remarks on that occasion. Versions of this material were also presented at Ann Arbor, Columbia, Girona, Harvard (as part of the second of my Whitehead Lectures in 2001), New York University and Oxford University. I am grateful to participants in those discussions, and thank also Paul Boghossian, Michael Dummett, Gilbert Harman, Philip Kitcher, Peter Railton, Stephen Schiffer, Ralph Wedgwood, Bernard Williams, Timothy Williamson and the referee for the European Journal of Philosophy for valuable comments.

\section{REFERENCES}

Ayer, A. (1946), Language, Truth and Logic. London: Gollancz.

Belnap, N. (1962), 'Tonk, Plonk and Plink', in Analysis 22, 130-34.

Boghossian, P. 'Analyticity', in A Companion to the Philosophy of Language, ed. R. Hale and C. Wright. Oxford: Blackwell.

BonJour, L. (1985), The Structure of Empirical Knowledge. Cambridge, Mass.: Harvard University Press.

Brandom, R. 2000, Articulating Reasons: An Introduction to Inferentialism. Cambridge, Mass.: Harvard University Press.

Burge, T., (1979), 'Individualism and the Mental', in Midwest Studies in Philosophy 4, 73-121.

Burge, T. (1993), 'Content Preservation', in Philosophical Review 102, 457-88.

Carnap, R. (1937), The Logical Syntax of Language, tr. A. Smeaton. New York: Harcourt Brace.

Cassam, Q. (2000), 'Rationalism, Empiricism and the A Priori', in New Essays on the A Priori ed. P. Boghossian and C. Peacocke. Oxford: Oxford University Press.

Davidson, D. (2001), 'On the Very Idea of a Conceptual Scheme', repr. in his Inquiries into Truth and Interpretation. Oxford: Oxford University Press.

Dummett, M. (1973), Frege: Philosophy of Language. London: Duckworth.

Dummett, M. (1978), 'The Significance of Quine's Indeterminacy Thesis', repr. in his Truth and Other Enigmas. Duckworth, London 1978.

Frege, G. (1998), Grundgesetze der Arithmetik. Hildesheim: Olms.

Goldman, A. (1986), Epistemology and Cognition. Cambridge, Mass.: Harvard University Press.

Gödel, K. (1995), Collected Works Volume III, ed. S. Feferman, J Dawson Jr., W. Goldfarb, C. Parsons, R. Solovay. New York: Oxford University Press.

Leibniz, G. (1981), New Essays on Human Understanding, tr. J. Bennett and P. Remnant. Cambridge: Cambridge University Press.

(c) Blackwell Publishers Ltd. 2002 
Nozick, R. (1981), Philosophical Explanations. Cambridge, Mass.: Harvard University Press.

Peacocke, C. (1992), A Study of Concepts. Cambridge, Mass.: MIT Press.

Peacocke, C. (1993a), 'How Are A Priori Truths Possible?', in the European Journal of Philosophy 1, 175-99.

Peacocke, C. (1993b), 'Proof and Truth', in Reality, Representation and Projection, ed. J. Haldane and C. Wright. Oxford: Oxford University Press.

Peacocke, C. (1998), 'The Philosophy of Language', in Philosophy 2: Further Through the Subject, ed. A. Grayling. Oxford: Oxford University Press.

Peacocke, C. (1999), Being Known. Oxford: Oxford University Press.

Peacocke, C. (2001a), 'Understanding the Past Tense', in Time and Memory, ed. C. Hoerl and T. McCormack. Oxford: Oxford University Press.

Peacocke, C. (2001b), 'Does Perception have a Nonconceptual Content?', in the Journal of Philosophy 98, 239-64.

Peacocke, C. (2001c), 'The Past, Necessity, Externalism and Entitlement', in Philosophical Books, 42, 106-17.

Peacocke, C. (2003), 'The A Priori', in The Oxford Handbook of Analytical Philosophy, ed. F. Jackson and M. Smith. Oxford: Oxford University Press.

Prior, A. (1960), 'The Runabout Inference Ticket' Analysis 21, 38-9.

Putnam, H. (1975), 'The Meaning of 'Meaning' in his Mind, Language and Reality. Cambridge: Cambridge University Press.

Putnam, H. (1995), Pragmatism (Oxford: Blackwell).

Quine, W. (1951), 'Two Dogmas of Empiricism', Philosophical Review 60, $20-43$.

Quine, W. (1974), The Roots of Reference. LaSalle, Illinois: Open Court.

Quine, W. (1976), The Ways of Paradox and Other Essays, Revised Edition. Cambridge, Mass.: Harvard University Press.

Rorty, R. (2001), 'An Imaginative Philosopher: the Legacy of W. V. Quine', in The Chronicle of Higher Education, February 2, B7-B9.

(C) Blackwell Publishers Ltd. 2002 